\title{
Stroke at baseline of the Brazilian Longitudinal Study of Adult Health (ELSA-Brasil): a cross-sectional analysis
}

\author{
Fernanda Gabriela de Abreu', Alessandra Carvalho Goulart", Marina Gabriela Birck'II, Isabela Martins Benseñor ${ }^{\text {IV }}$ \\ Centro de Pesquisa Clínica e Epidemiológica (CPCE), Hospital Universitário (HU), Universidade de São Paulo (USP), São Paulo (SP), Brazil
}

'Master's Student, Faculdade de Medicina da Universidade de São Paulo (FMUSP), São Paulo (SP), Brazil.

(D)orcid.org/0000-0002-0025-1147. "MD, PhD. Assistant Professor, Centro de Pesquisa Clínica e Epidemiológica, Hospital Universitário, Universidade de São Paulo (USP), São Paulo (SP), Brazil.

(D)orcid.org/0000-0003-1076-5210

'"DPH. Master's Student, Faculdade de Medicina da Universidade de São Paulo (FMUSP), and Associate Professor, Department of Internal Medicine, FMUSP, São Paulo (SP), Brazil.

(Dorcid.org/0000-0003-3003-1839

"MD, PhD. Associate Professor, Department of Internal Medicine, School of Medicine, Universidade de São Paulo (USP), and Assistant Professor, Centro de Pesquisa Clínica e Epidemiológica, Hospital Universitário, Universidade de São Paulo, São Paulo (SP), Brazil.

(Dorcid.org/0000-0002-6723-5678

KEY WORDS:

Cerebrovascular disorders.

Stroke.

Risk factor.

Secondary prevention.

\begin{abstract}
BACKGROUND: Secondary prevention of stroke is a very important goal for achieving continuous reduction in stroke mortality rates over the next decades.

DESIGN AND SETTING: Cross-sectional analysis on the Brazilian Longitudinal Study of Adult Health (ELSA-Brasil), with data from Salvador, Vitória, Belo Horizonte, Rio de Janeiro, São Paulo and Porto Alegre. METHODS: This descriptive analysis focused on secondary prevention of stroke among participants who self-reported a medical diagnosis of stroke at the baseline of ELSA-Brasil, and its association with sociodemographic characteristics.

RESULTS: Overall, 197 participants (1.3\%) reported a prior medical history of stroke. Participants with stroke were older and less educated and had lower mean monthly family income, compared with nonstroke participants. Among all stroke cases, $23.7 \%$ did not use any medication for secondary prevention of stroke. Use of secondary prevention was higher among men than among women (respectively, $59.6 \%$ versus $40.4 \% ; \mathrm{P}=0.02$ for aspirin; and $71.4 \%$ versus $28.6 \% ; \mathrm{P}=0.04$ for other antiplatelet drugs). Having private health insurance was associated with greater use of less cost-effective and more expensive medications (like angiotensinogen receptor blockers) and a tendency to use antiplatelet drugs other than aspirin, among participants reporting stroke, compared with others. Use of medication decreased as time passed after suffering a stroke.

CONCLUSIONS: In this sample of individuals with better access to healthcare services, use of secondary prevention for stroke was low, which may suggest that the situation in the general population is worse. Sex was the most important sociodemographic variable associated with low use of secondary prevention.
\end{abstract}

\section{INTRODUCTION}

Despite the declining stroke rates over recent years, with a reduction of $21 \%$ from 2005 to 2015 (19.2\% to $22.8 \%),{ }^{1}$ stroke remains one of the leading causes of mortality worldwide, particularly in developing countries. ${ }^{1,2}$ In Brazil, early mortality (at ages of less than 70 years) has presented an impressive decline since 2005 , from $55.7 \%$ in that year to $30.5 \%$ in 2015 , but is still very high. ${ }^{3}$ Although the risk of death due to stroke is decreasing in all regions of Brazil, faster declines were observed in the wealthiest areas, thus exacerbating the social inequalities in the country. 4

Secondary prevention of stroke mortality is a key point in relation to achieving continuous reduction in stroke mortality over the next decades. However, few studies in Brazil provide information about use of secondary prevention. In Joinville, a city in southern Brazil, out of 594 patients who were discharged from public hospitals after their first stroke, $54 \%$ did not return to a public or private hospital unit for follow-up at least twice a year; 5.7\% (34/594) stated that they were not taking any secondary preventive treatment, had no intention of coming back for secondary prevention, or had no intention of taking the hospital prescription; $8.4 \%$ (50/594) looked for private care or for public healthcare units outside their health district; and 8.4\% (50/594) were lost, despite thorough searching for them. ${ }^{6}$ In another study in Pelotas (also in the southern region), the rate of use of aspirin for secondary prevention of stroke, angina pectoris and myocardial infarction was $34.3 \%$, i.e. well below the recommended levels for prevention of cardiovascular diseases. ${ }^{7}$

Considering the paucity of studies evaluating secondary prevention for stroke in Brazil, we sought to conduct a cross-sectional analysis on the frequency of secondary prevention of stroke and associated sociodemographic risk factors, using data from participants who reported 
having a previous medical diagnosis of stroke at the baseline examination of the Brazilian Longitudinal Study of Adult Health (ELSA-Brasil).

In this context, we performed a cross-sectional analysis with the main objective of evaluating secondary prevention of stroke among the participants of the Brazilian Longitudinal Study of Adult Health (ELSA-Brasil), using self-reported information on previous stroke that was obtained at the baseline examination.

\section{METHODS}

\section{Study design and participants}

ELSA-Brasil is a cohort study on 15,105 civil servants aged 35 to 74 years living in six cities (Belo Horizonte, Porto Alegre, Rio de Janeiro, Salvador, São Paulo and Vitória). It was designed to investigate cardiovascular diseases and diabetes and their risk factors. ${ }^{8}$ The baseline assessment took place between August 2008 and December 2010. Previous reports presented more details about the study design, concept and sampling procedures. ${ }^{8,9-10}$

In this analysis, we included all participants for whom selfreported information about stroke $(\mathrm{N}=15,102)$ was available from the baseline assessment. All participants answered a question asking about a previous medical diagnosis of stroke.

Each participant was interviewed at the workplace and made a visit to the research center for clinical examinations, in accordance with standard protocols. The interviews and examinations at each site were conducted by trained personal under strict quality control. ${ }^{10}$

\section{Variables}

For the present analysis, the following sociodemographic variables were considered: age (years), sex, self-reported race (white, mixed race, black, Asian or indigenous), educational attainment (less than high school; high school and some tertiary education; or completed college/university or more), mean monthly family income ( $\leq$ US $\$ 1,245$; US $\$ 1,246$ to US $\$ 3,319$; or $\geq$ US $\$ 3,320$ ) and having private health insurance (\%). Local currency (Brazilian reais, BRL) was converted to United States dollars (USD) at a rate of BRL $2.00=$ USD 1.00 in December 2008.

Smoking and alcohol use were categorized as never, past or current. ${ }^{10}$ Leisure-time physical activity was measured by means of the International Physical Activity Questionnaire (IPAQ), in its long form, and the subjects were classified in accordance with the World Health Organization criteria, as physically active, partly active or sedentary. Adherence to medication was assessed using simple questions asking about the frequency of use of medicines.

Anthropometric measurements were obtained using standard protocols. Body mass index was calculated as weight divided by height squared $\left(\mathrm{kg} / \mathrm{m}^{2}\right)$. Blood pressure (BP) was taken using a validated oscillometric device, the Omron HEM 705CPINT.
Three measurements were taken at one-minute intervals. The mean of the latest two BP measurements was taken to be the value for defining situations of high BP.

Presence of hypertension was defined as situations in which medications to treat hypertension were being used, or of systolic blood pressure $\geq 140 \mathrm{mmHg}$ or diastolic blood pressure $\geq 90 \mathrm{mmHg}$. Presence of diabetes was defined as situations in which there was a previous medical history of diabetes, medications to treat diabetes were being used, or situations of fasting plasma glucose $\geq 126 \mathrm{mg} / \mathrm{dl}$, two-hour plasma glucose $\geq 200 \mathrm{mg} / \mathrm{dl}$, or HbA1C $\geq 6.5 \%$. Presence of dyslipidemia was defined as situations in which lipid-lowering treatment was being used or of LDL-cholesterol (LDL-c) $\geq 130 \mathrm{mg} / \mathrm{dl} .{ }^{10}$ The glomerular filtration rate (GFR) was calculated by means of the Chronic Kidney Disease Epidemiology Collaboration (CKD-Epi) equation.

\section{Use of medication}

All participants were asked about their continuous use of prescription or non-prescription medicines and over-the-counter drugs, including pills or liquid medications. Participants were instructed to bring all their medications to the ELSA-Brasil research centers. Then, all medications taken during the last two weeks were reviewed during the baseline assessment.

The medications used were classified as antithrombotics, including anticoagulants (antivitamin K), heparin and antiplatelet medications; as different classes of antihypertensives, such as diuretics, $\beta$-blockers, angiotensin-converting enzyme inhibitors (ACEI), angiotensinogen receptor blockers (ARB), calcium channel blockers (CCB), vasodilators, central action and alpha-blockers; or as lipid-lowering drugs (statins and others). Medication adherence was assessed using these four questions and by asking participants to bring medications for checking in the ELSA centers (as stated above).

Conventional 12-lead electrocardiograms (ECGs) were performed using a digital device (Atria 6100, Cardiac Science Corporation, Deerfield, Wisconsin, USA) with automated readings. The technique used for carotid intima-media thickness (CIMT) measurement in ELSA-Brasil was published previously. ${ }^{11}$ The same protocol was applied at all the sites, using a Toshiba (Aplio XG) with a $7.5 \mathrm{MHz}$ linear transducer. We used MIA software to standardize the reading and interpretation of carotid scans. ${ }^{12}$

\section{Statistical analysis}

Cross-sectional associations with self-reported stroke, the main sociodemographic characteristics, the cerebrovascular risk factors and the use of medications for stroke secondary prevention were analyzed. Categorical variables were presented as absolute counts and proportions and were compared using the chi-square test. Continuous variables were presented as means $( \pm$ standard deviation, SD) and were compared using one-way analysis of 
variance (ANOVA); or as medians (with interquartile range, IQR) and were compared using the Mann-Whitney test, as necessary.

The relationships between stroke, main cerebrovascular risk factors and the use of medications for secondary prevention of stroke were tested using logistic regression models. Odds ratios (OR) with their respective $95 \%$ confidence interval (95\% CI) were presented as crude ratios, as age and sex-adjusted ratios and as ratios with multivariate adjustment including age, sex, education, mean family monthly income and private health insurance.

All the analyses were performed using the Statistical Package for the Social Sciences, version 22 (SPSS Inc., Chicago, Illinois, USA). P-values $<0.05$ were considered statistically significant.

\section{Ethics statement}

The ELSA-Brasil study was approved at all six centers by their institutional review boards addressing research on human participants, in accordance with the Declaration of Helsinki (approval number CEP-HU/USP: 1555/16). Written informed consent was obtained from all participants. ${ }^{8}$

\section{RESULTS}

Overall, 197 participants (1.3\%) reported having a prior medical history of stroke. The participants with stroke were older and less educated and had lower mean monthly family income, larger waist circumference, higher systolic and diastolic blood pressure measurements and higher frequencies of hypertension, diabetes, dyslipidemia and chronic kidney disease, compared with nonstroke subjects. They reported less frequent alcohol intake than did the participants who did not report having had stroke at the baseline.

The mean CIMT values were higher among subjects who reported having had a stroke than among the other participants without this condition (Table 1). Except for $\alpha$-blockers, which are not used for stroke participants, all classes of antihypertensive drugs were used at higher frequencies among the stroke participants than among the non-stroke participants (Table 1). Adherence to use of any medication was higher among the stroke participants than among the other participants: $46 \%$ among stroke participants versus $37.1 \%$ among non-stroke participants $(\mathrm{P}=0.02)$. However, neither of these frequencies of use was very high.

In the bivariate analysis, the participants with stroke reported making greater use of aspirin, other antiplatelet drugs and anticoagulants (antivitamin K) (Table 2), compared with non-stroke participants (Table 2). Although there was no difference in the frequency of stroke according to sex, it was noticed that the men made greater use of aspirin (respectively, 59.6\% versus $40.4 \%$; $\mathrm{P}=0.02$ ) and greater use of other antiplatelet drugs (respectively, $71.4 \%$ versus $28.6 \% ; \mathrm{P}=0.04$ ), and that there was a trend towards greater use of antivitamin $\mathrm{K}$ drugs (respectively, $83.3 \%$ versus $16.7 \%$; P-value $=0.056$ ), compared with the women. Having private
Table 1. Sociodemographic and clinical characteristics and use of medication for secondary prevention, according to self-reported occurrences of stroke at the baseline examination of ELSA-Brasil

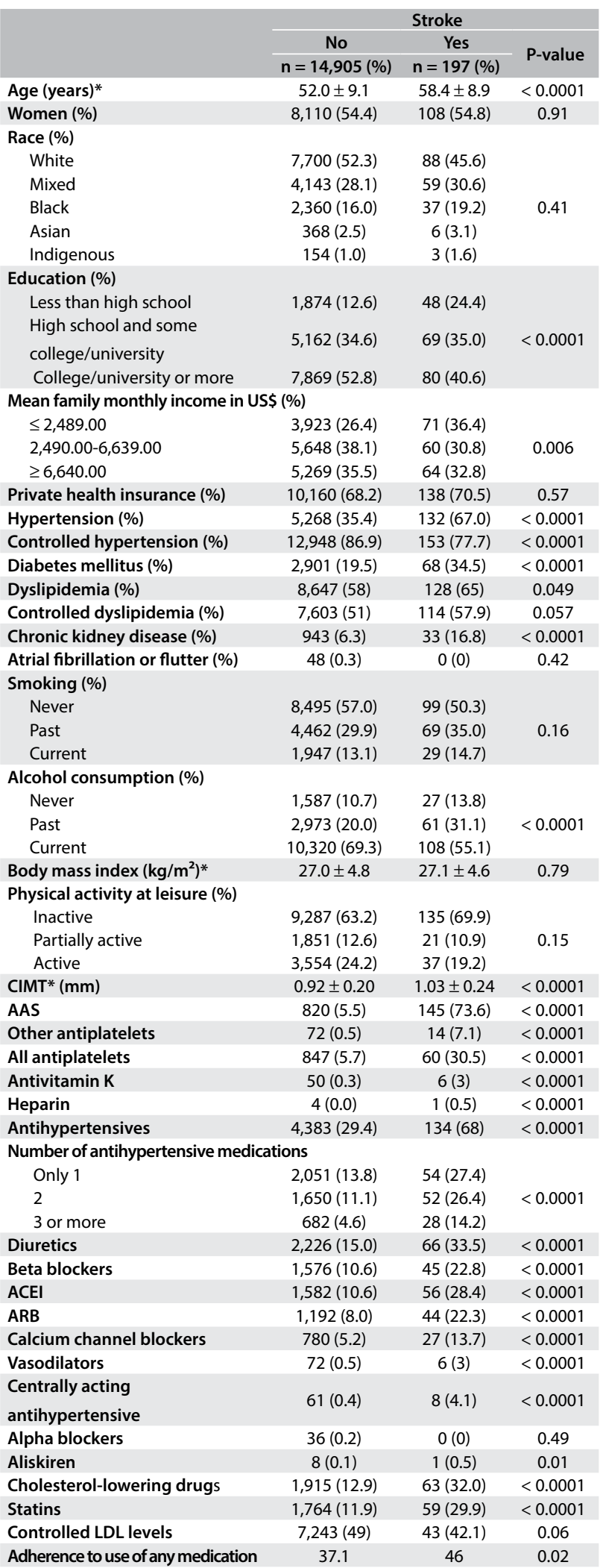

CIMT = carotid intima-media thickness; AAS = acetylsalicylic acid, ACEI = angiotensin-converting enzyme inhibitors; $A R B=$ angiotensin receptor blockers. *Data are presented as means ( \pm standard deviation). 
health insurance was not associated with higher use of other antiplatelet drugs.

Table 3 shows the main classes of anti-hypertensive drugs used for stroke secondary prevention: diuretics, beta-blockers, angiotensin-converting enzyme inhibitors (ACEI), angiotensinogen receptor blockers (ARB) and calcium channel blockers (CCB). The most frequently used antihypertensive medication in the sample was diuretics, followed by ACEI, $\beta$-blockers, ARB, CCB, centrally acting hypertensives and vasodilators. No difference in the use of antihypertensive drugs was found between men and women, except

Table 2. Use of main antiplatelet and anticoagulant drugs in secondary prevention of stroke

\begin{tabular}{|c|c|c|c|c|c|c|c|c|c|}
\hline & \multicolumn{2}{|c|}{ AAS } & \multirow{3}{*}{ P-value } & \multicolumn{2}{|c|}{ Other antiplatelets } & \multirow{3}{*}{ P-value } & \multicolumn{2}{|c|}{ Antivitamin $\mathrm{K}$} & \multirow{3}{*}{ P-value } \\
\hline & No & Yes & & No & Yes & & No & Yes & \\
\hline & $n=145(\%)$ & $n=52(\%)$ & & $n=183(\%)$ & $n=14(\%)$ & & $n=191(\%)$ & $n=6(\%)$ & \\
\hline Age (years)* & $58(8.7)$ & $59.4(9.5)$ & 0.37 & $57.9(8.6)$ & $64.5(9.9)$ & & $58.2(8.9)$ & $64.5(6)$ & 0.09 \\
\hline \multicolumn{10}{|l|}{ Sex $(\%)$} \\
\hline Male & $58(40)$ & 31 (59.6) & \multirow{2}{*}{0.02} & $79(43.2)$ & $10(71.4)$ & \multirow{2}{*}{0.04} & $84(44.0)$ & $5(83.3)$ & \multirow{2}{*}{0.056} \\
\hline Female & $87(60)$ & $21(40.4)$ & & $104(56.8)$ & $4(28.6)$ & & $107(56.0)$ & $1(16.7)$ & \\
\hline \multicolumn{10}{|l|}{ Race (\%) } \\
\hline White & $60(42.3)$ & $28(54.9)$ & \multirow{5}{*}{0.58} & $80(44.4)$ & $8(61.5)$ & & $84(44.7)$ & $4(80.0)$ & \multirow{5}{*}{0.60} \\
\hline Mixed & $47(33.1)$ & $12(23.5)$ & & $56(31.1)$ & $3(23.1)$ & & $58(30.9)$ & $1(20.0)$ & \\
\hline Black & $28(19.7)$ & $9(17.6)$ & & $35(19.4)$ & $2(15.4)$ & 0.78 & $37(19.7)$ & $0(0.0)$ & \\
\hline Asian & $5(3.5)$ & $1(2)$ & & $6(3.3)$ & $0(0)$ & & $6(3.2)$ & $0(0.0)$ & \\
\hline Indigenous & $2(1.4)$ & $1(2)$ & & $1(1.7)$ & $0(0)$ & & $3(1.6)$ & $0(0.0)$ & \\
\hline \multicolumn{10}{|l|}{ Education (\%) } \\
\hline Less than high school & $34(23.4)$ & $14(26.9)$ & \multirow{3}{*}{0.87} & $44(24)$ & $4(28.6)$ & \multirow{3}{*}{0.23} & $47(24.6)$ & $1(16.7)$ & \multirow{3}{*}{0.41} \\
\hline $\begin{array}{l}\text { High school and some } \\
\text { college/university }\end{array}$ & $51(35.2)$ & $18(34.6)$ & & $67(36.6)$ & $2(14.3)$ & & $68(35.6)$ & $1(16.7)$ & \\
\hline College/university or more & $60(41.4)$ & $20(38.5)$ & & $72(39.3)$ & $8(57.1)$ & & $76(39.8)$ & $4(66.7)$ & \\
\hline \multicolumn{10}{|c|}{ Mean monthly family income (\%) } \\
\hline$\leq$ USD 1245 & $54(37.8)$ & $17(32.7)$ & \multirow{3}{*}{0.75} & $68(37.4)$ & $3(23.1)$ & \multirow{3}{*}{0.49} & $71(37.6)$ & $0(0.0)$ & \multirow{3}{*}{0.11} \\
\hline USD 1246 to 3319 & $44(30.8)$ & $16(30.8)$ & & $56(30.8)$ & $4(30.8)$ & & $58(30.7)$ & $2(33.3)$ & \\
\hline$\geq$ USD 3320 & $45(31.5)$ & $19(36.5)$ & & $58(31.9)$ & $6(46.2)$ & & $60(31.7)$ & $4(66.7)$ & \\
\hline Private health insurance (\%) & $103(71)$ & $35(67.3)$ & 0.62 & $125(68.3)$ & $13(92.9)$ & 0.053 & 133 (69.6) & $5(83.3)$ & 0.47 \\
\hline
\end{tabular}

AAS = acetylsalicylic acid; USD = United States dollars.

Table 3. Main classes of antihypertensive drugs used for secondary prevention of stroke

\begin{tabular}{|c|c|c|c|c|c|c|c|c|c|c|c|c|c|c|c|}
\hline & \multicolumn{2}{|c|}{ Diuretics } & \multirow{3}{*}{$\mathbf{P}$} & \multicolumn{2}{|c|}{ Beta-blockers } & \multirow{3}{*}{$\mathbf{P}$} & \multicolumn{2}{|c|}{ ACEI } & \multirow{3}{*}{$P$} & \multicolumn{2}{|c|}{ ARB } & \multirow{3}{*}{$\mathbf{P}$} & \multicolumn{2}{|c|}{$\begin{array}{l}\text { Calcium channel } \\
\text { blockers }\end{array}$} & \multirow{3}{*}{$\mathbf{P}$} \\
\hline & No & Yes & & No & Yes & & No & Yes & & No & Yes & & No & Yes & \\
\hline & $n=131(\%)$ & $n=66(\%)$ & & $n=152(\%)$ & $n=45(\%)$ & & $n=141(\%)$ & $n=56(\%)$ & & $n=153(\%)$ & $n=44(\%)$ & & $n=170(\%)$ & $n=27(\%)$ & \\
\hline Age (years)* & $57.2(8.4)$ & $60(9.4)$ & 0.009 & $58(8.7)$ & $60(9.3)$ & 0.22 & $58.3(9.1)$ & $58.6(8.4)$ & 0.81 & $57(8.9)$ & $63(7.2)$ & $<0.0001$ & $57.7(9)$ & $62.8(6.9)$ & 0.005 \\
\hline \multicolumn{16}{|l|}{ Sex (\%) } \\
\hline Female & $72(55.0)$ & $36(54.5)$ & \multirow{2}{*}{0.96} & $86(56.6)$ & $22(48.9)$ & \multirow{2}{*}{0.36} & $84(59.6)$ & 24 (42.9) & \multirow{2}{*}{0.03} & $86(56.2)$ & $22(50.0)$ & \multirow{2}{*}{0.47} & 95 (55.9) & $13(48.1)$ & \multirow{2}{*}{0.45} \\
\hline Male & $59(45)$ & $30(45.5)$ & & $66(43.4)$ & $23(51.1)$ & & $57(40.4)$ & $31(57.1)$ & & $67(43.8)$ & $22(50.0)$ & & $75(44.1)$ & 14 (51.9) & \\
\hline \multicolumn{16}{|l|}{ Race (\%) } \\
\hline White & $66(52.0)$ & $22(33.3)$ & \multirow{5}{*}{0.006} & $68(45.6)$ & $20(45.5)$ & \multirow{5}{*}{0.23} & $65(47.1)$ & $23(41.8)$ & \multirow{5}{*}{0.62} & $72(48.3)$ & $16(36.4)$ & \multirow{5}{*}{0.27} & $79(47.3)$ & $9(34.6)$ & \multirow{5}{*}{0.04} \\
\hline Mixed & $31(24.4)$ & $28(42.4)$ & & 49 (32.9) & $10(22.7)$ & & $38(27.5)$ & $21(38.2)$ & & $44(29.5)$ & $15(34.1)$ & & $51(30.5)$ & $8(30.8)$ & \\
\hline Black & $25(19.7)$ & $12(18.2)$ & & $26(17.4)$ & $11(25.0)$ & & $29(21.0)$ & $8(14.5)$ & & $25(16.8)$ & $12(27.3)$ & & $30(18.0)$ & 7 (26.9) & \\
\hline Asian & $5(3.9)$ & $1(1.5)$ & & $5(3.4)$ & $1(2.3)$ & & $4(2.9)$ & $2(3.6)$ & & $6(4.0)$ & $0(0.0)$ & & $6(3.6)$ & $0(0.0)$ & \\
\hline Indigenous & $0(0.0)$ & $3(4.5)$ & & $1(0.7)$ & $2(4.5)$ & & $2(1.4)$ & $1(1.8)$ & & $2(1.3)$ & $1(2.3)$ & & $1(0.6)$ & $2(7.7)$ & \\
\hline \multicolumn{16}{|l|}{ Education (\%) } \\
\hline$<$ High school & $27(20.6)$ & $21(31.8)$ & \multirow{3}{*}{0.21} & $39(25.7)$ & $9(20.0)$ & \multirow{3}{*}{0.32} & $30(21.3)$ & $18(32.1)$ & \multirow{3}{*}{0.19} & $37(24.2)$ & $11(25.0)$ & \multirow{3}{*}{0.43} & $37(21.8)$ & $11(40.7)$ & \multirow{3}{*}{0.10} \\
\hline $\begin{array}{l}\text { High school/ } \\
\text { some college/ } \\
\text { university }\end{array}$ & $47(35.9)$ & $22(33.3)$ & & $49(32.2)$ & $20(44.4)$ & & $49(34.8)$ & $20(35.7)$ & & $57(37.3)$ & $12(27.3)$ & & $62(36.5)$ & $7(25.9)$ & \\
\hline $\begin{array}{l}\text { College/university } \\
\text { or more }\end{array}$ & $57(43.5)$ & $23(34.8)$ & & $64(42.1)$ & $16(35.6)$ & & $62(44.0)$ & $18(32.1)$ & & $59(38.6)$ & $21(47.7)$ & & $71(41.8)$ & $9(33.3)$ & \\
\hline \multicolumn{16}{|c|}{ Mean monthly family income (\%) } \\
\hline$\leq$ USD 1245 & $44(34.1)$ & $27(40.9)$ & \multirow{3}{*}{0.50} & $55(36.7)$ & $16(35.6)$ & & $49(35.3)$ & $22(39.3)$ & & $59(39.1)$ & $12(27.3)$ & & $60(35.5)$ & $11(42.3)$ & \\
\hline USD 1246 to 3319 & $43(33.3)$ & $17(25.8)$ & & $47(31.3)$ & $13(28.9)$ & 0.90 & $41(29.5)$ & 19 (33.9) & 0.52 & $47(31.1)$ & $13(29.5)$ & 0.20 & $52(30.8)$ & $8(30.8)$ & 0.74 \\
\hline$\geq$ USD 3320 & $42(32.6)$ & $22(33.3)$ & & $48(32.0)$ & $16(35.6)$ & & $49(35.3)$ & $15(26.8)$ & & $45(29.8)$ & $19(43.2)$ & & $57(33.7)$ & $7(26.9)$ & \\
\hline $\begin{array}{l}\text { Private health } \\
\text { insurance (\%) }\end{array}$ & $97(74.0)$ & $41(62.1)$ & 0.09 & $105(69.1)$ & $33(73.3)$ & 0.58 & $107(77.9)$ & $31(55.4)$ & 0.005 & $100(65.4)$ & $38(86.4)$ & 0.007 & $120(70.6)$ & $18(66.7)$ & 0.68 \\
\hline
\end{tabular}

$\mathrm{ACEI}=$ angiotensin-converting enzyme inhibitors; $\mathrm{ARB}=$ angiotensin receptor blockers. 
for ACEI, for which there was greater use among men than among woman $(57.1 \%$ versus $42.9 \%$; $\mathrm{P}$-value $=0.03$ ).

Lower frequency of diuretic use was observed among whites with stroke and higher frequency of diuretic use was observed among mixed-race participants with stroke, compared with others $(P=0.006)$. Furthermore, lower frequency of CCB use was noticed among whites with stroke and higher frequency of CCB use among black participants with stroke, compared with others without this condition $(\mathrm{P}=0.04)$.

Regarding educational attainment, use of centrally acting antihypertensive medication was higher among stroke participants with less education than among participants with higher levels of education. Having private health insurance was associated with higher use of ARB among stroke participants, compared with others.

Use of statins was also greater among older participants $(\mathrm{P}<0.0001)$ and among men in comparison with women $(64.4 \%$ versus 35.6\%; $\mathrm{P}<0.0001)$. Stroke participants reported making greater use of statins, compared with non-stroke participants. The frequency of use of statins was higher among white participants with stroke, compared with others $(\mathrm{P}=0.04)$ (Table 4).

Table 5 shows the use of medication according to the time that had elapsed since the stroke. Absence of use of medication increased with increasing length of time since the stroke, such that around $20 \%$ of the participants for whom 10 years or less had elapsed since their stroke were not using medication and around $30 \%$ of the participants who reported that 11 years or more had

Table 4. Characteristics of participants with stroke according to use of statins

\begin{tabular}{|c|c|c|c|}
\hline & \multicolumn{3}{|c|}{ Use of statins } \\
\hline & No & Yes & \multirow{2}{*}{ P-value } \\
\hline & $n=138(\%)$ & $\mathrm{n}=59(\%)$ & \\
\hline Age (years)* & $56.7(8.7)$ & $62.3(8.2)$ & $<0.0001$ \\
\hline \multicolumn{4}{|l|}{ Sex $(\%)$} \\
\hline Male & $51(37.0)$ & $38(64.4)$ & \multirow{2}{*}{$<0.0001$} \\
\hline Female & $87(63.0)$ & $21(35.6)$ & \\
\hline \multicolumn{4}{|l|}{ Race (\%) } \\
\hline White & $54(39.7)$ & $34(59.6)$ & \multirow{5}{*}{0.04} \\
\hline Mixed race & $45(33.1)$ & $14(24.6)$ & \\
\hline Black & $31(22.8)$ & $6(10.5)$ & \\
\hline Asian & $3(2.2)$ & $3(5.3)$ & \\
\hline Indigenous & $3(2.2)$ & $0(0.0)$ & \\
\hline \multicolumn{4}{|l|}{ Years of education (\%) } \\
\hline$<9$ & $35(25.4)$ & $13(22.0)$ & \multirow{3}{*}{0.44} \\
\hline $9-11$ & $51(37.0)$ & $18(30.5)$ & \\
\hline$>11$ & $52(37.7)$ & $28(47.5)$ & \\
\hline \multicolumn{4}{|c|}{ Mean family monthly income (\%) } \\
\hline$\leq$ USD 1245 & $55(40.1)$ & $16(27.6)$ & \multirow{3}{*}{0.11} \\
\hline USD 1246 to 3319 & $43(31.4)$ & $17(29.3)$ & \\
\hline$\geq$ USD 3320 & $39(28.5)$ & $25(43.1)$ & \\
\hline \multicolumn{4}{|c|}{ Private health insurance (\%) } \\
\hline No & $44(31.9)$ & $15(25.4)$ & \multirow{2}{*}{0.37} \\
\hline Yes & 94 (68.1) & 44 (74.6) & \\
\hline
\end{tabular}

elapsed since their stroke were not using medication. Overall, the use of medication for secondary stroke prevention was very low in this sample and it declined with increasing length of time since the stroke. The percentage of the participants who reported using at least one antiplatelet or anticoagulant drug in association with antihypertensives and statins was around $15 \%$ to $20 \%$.

\section{DISCUSSION}

Overall, the use of medication was very low among these participants in ELSA-Brasil, despite the existence of cheap medications such as aspirin or $\beta$-blockers, and a national policy that guarantees access to essential medications for all citizens.

Although the frequencies of stroke according to sex were similar (no statistical difference), the men reported making greater use of medication for secondary prevention of stroke than did women. Recent data on the prevalence of stroke from the National Health Survey (Pesquisa Nacional de Saúde, PNS) and from the Global Burden of Disease Brasil study have also shown similar results. ${ }^{3,6}$ If the prevalence is similar between the sexes, and considering that women use healthcare services more frequently than men do, ${ }^{14-16}$ it might have been expected that women would have higher use of medication than men.

The data from ELSA-Brasil showed that the prevalence rates regarding awareness about being hypertensive, use of medication and control of high blood pressure were higher among women than among men. The same was true for use of statins. One possible explanation is that participants who reported having had a stroke presented lower mean monthly family income than did nonstroke participants. Moreover, from analysis on the data according to sex, it could be seen that women who reported having had a stroke presented lower income than did men who reported having had a stroke. Discussion of adherence to treatment is also a complex matter since it is likely that some participants, especially women, had not had any treatment prescribed and thus were not taking any medication. Therefore, our results are similar to those from a previous Brazilian study that reported that there was only low use of medication for chronic diseases. ${ }^{17}$

Our data highlighted some important points. ELSA-Brasil participants are civil servants with higher levels of education, higher mean monthly family income and better access to medical services, compared with the general Brazilian population. However, even considering this better access to medical services, the frequency at which participants who had had a stroke reported using antiplatelet or anticoagulant drugs in association with antihypertensives and statins was never higher than $21 \%$. Nonuse of medication was less than $20 \%$ among individuals who had had a stroke ten years or less before their baseline interview, but this rose to more than $30 \%$ among those whose stroke was more than 10 years earlier. Frequency of use of medication also declined according to the length of time since the stroke. 
Brazil has implemented a national drug policy to guarantee access to essential drugs for all citizens. ${ }^{18}$ Drugs used for secondary prevention of stroke are in the list of essential drug products (RENAME).${ }^{19}$ The Ministry of Health has also created the Brazilian Popular Pharmacy Program (FPB $)^{20}$ with the aim of increasing access to essential and primary medicines for all citizens. ${ }^{21,22}$

Although these drugs should be available for all individuals, some studies have indicated that not all antiplatelet or antihypertensive medications are always available through public healthcare system. ${ }^{23,24}$ It is important to note that at the time of the baseline examinations in ELSA-Brasil (between August 2008 and December 2010) only two antihypertensive medications were included in the Popular Pharmacy Program: beta blockers and ACEI. In 2010, statins and ARB were also included, and aspirin was added in 2011. Although our data did not show any difference in the use of secondary prevention according to mean monthly family income, it would be interesting to investigate the extent to which secondary prevention was being used at the time of the second ELSA-Brasil examination (conducted between 2012 and 2014). At that time, all the drugs used for prevention were available through all programs.

The pattern of statin use that we observed is similar to that presented in the Reasons for Geographic and Racial Differences in Stroke Study (REGARDS). Data from that study showed that the use of medication was highest among white men followed by the levels among black men, white women and black women. ${ }^{25}$ One potential explanation for the more aggressive use of statins among white men relative to the other groups may lie in physicians' treatment patterns and habits. ${ }^{25}$ In 2004, Mosca et al. found that although primary care physicians widely supported the National Cholesterol Education Program's Third Adult Treatment Panel guidelines and coronary heart disease (CHD) risk stratification, less than half of these physicians implemented risk calculation tools in their clinical practice. This resulted in consistent underestimation of CHD risk, especially among women. ${ }^{26}$

Having private health insurance was associated with higher frequency of $\mathrm{ARB}$ prescription than of ACEI prescription and a borderline trend towards use of antiplatelet drugs other than aspirin, along with higher frequency of use of centrally acting antihypertensive drugs. These data suggest that participants with private health insurance are using less cost-effective and more expensive antihypertensive and antiplatelet medications, in comparison with participants without private health insurance. Although no information regarding the incidence of the main stroke subtypes (ischemic or hemorrhagic) was available from ELSA-Brasil, no participant who self-reported having had a stroke in this sample presented atrial fibrillation or flutter. This may explain the low use of anticoagulants in the sample.

Stroke is a preventable disease. There is now a growing body of evidence highlighting the importance of comprehensive risk factor management for improving survival among stroke participants, especially through detection, treatment and control of high blood pressure. ${ }^{27}$ Despite the good results from hypertension treatment that were achieved in one selected sample,${ }^{28}$ a recent meta-analysis based on ten Brazilian cross-sectional studies ${ }^{29}$ estimated that in Brazil in the 2000 s, only $24.1 \%$ of the cases of high blood pressure were kept under control. Although this percentage was comparable to that of other countries, ${ }^{30-32}$ it was still low.

Some authors have adopted the concept of epidemiological transition to describe trends among cardiovascular diseases. Briefly, there was firstly a shift from rheumatic heart disease to hypertensive disease and hemorrhagic stroke. In the next stage, there was a shift from hemorrhagic to ischemic stroke, and finally to $\mathrm{CHD}$ among middle-aged individuals. In the last stage, there was a switch from stroke to CHD mortality. ${ }^{32}$ Brazil is in the last stage

Table 5. Medication use according to drug classes and length of time since occurrence of stroke, among participants with self-reported stroke

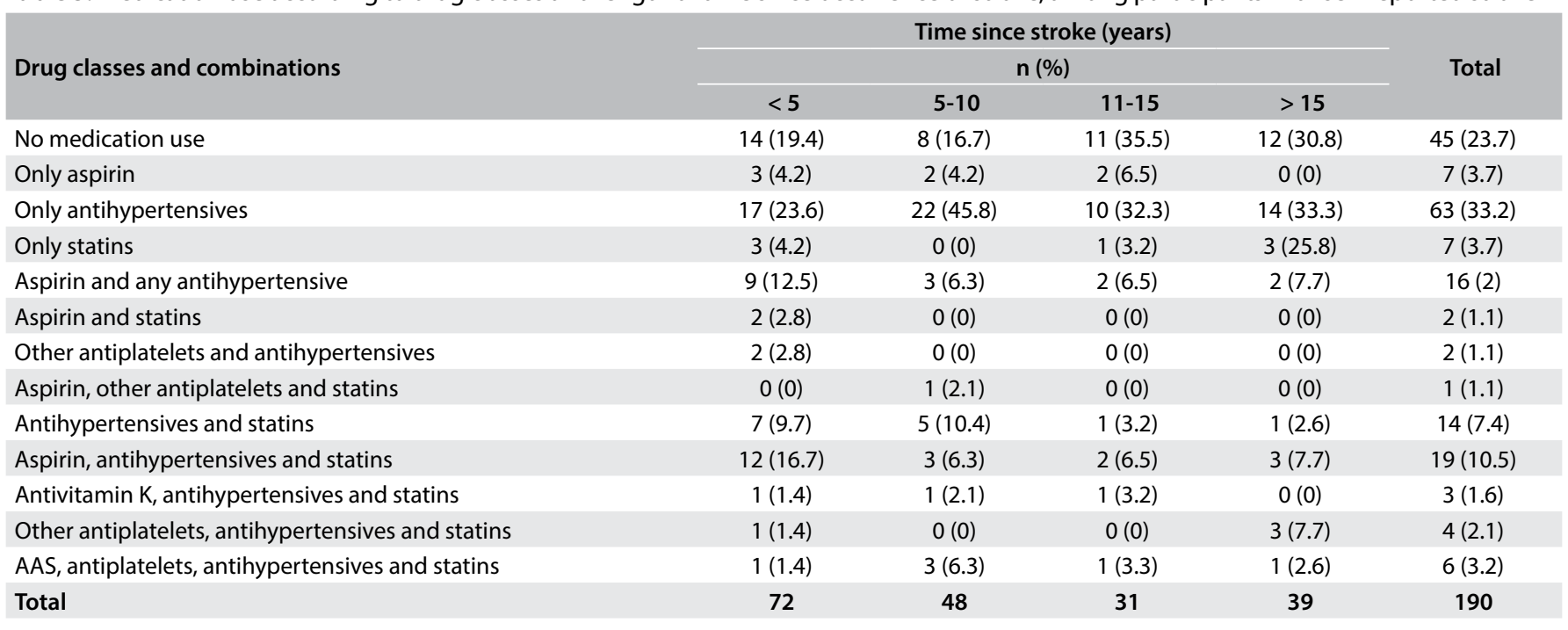


of this epidemiological transition. Around ten years ago (2007), ischemic heart diseases surpassed stroke as the most prevalent cause of death in this country. However, the burden of stroke is still very high and is associated with premature death.

In this sample from ELSA-Brasil, which had better access to healthcare and higher monthly income than that of the general population of Brazil, the frequency of use of secondary prevention was very low. This finding reaffirms that stroke is still a neglected disease in Brazil, ${ }^{34}$ and that this scenario has not changed over the last 10 years. ${ }^{33,34}$

This study had several limitations. The most important of these was that information about stroke in the baseline examination was self-reported, based on reports of previous medical diagnoses of stroke. Therefore, there was no information either about the frequency of the main subtypes of stroke (ischemic and hemorrhagic) or any confirmation of the diagnosis of stroke through medical records or imaging.

Recently, a study calculated the specificity of self-reported diagnoses of stroke using hospital data as the gold standard. It reported values of around $99 \%$, but with low sensitivity. ${ }^{35}$ In epidemiological studies, it is preferred to use questionnaires with greater specificity than sensitivity. Thus, in our study, self-reported occurrences of stroke were most likely true cases. However, milder cases that might have corresponded to minor stroke were likely to have remained undiagnosed as stroke. Thus, such cases would not be reported by ELSA-Brasil participants and, consequently, they are not included in this analysis. Therefore, it is still possible that there may have been some misclassification of cases of stroke in our study.

Interestingly, higher frequencies of risk factors and higher CIMT values were found among stroke participants than among other individuals without this condition, thus suggesting that the self-reported information indeed had value. Furthermore, detailed information about the participants' use of medication was available, and this provided an insight into the situation of secondary prevention of stroke in this sample. However, we did not have access to the medical reasons for prescribing specific medications to specific patients. Moreover, the eligibility criteria for ELSA-Brasil excluded individuals with communication problems or with cognitive deficits, which probably excluded some stroke cases. Hence, cases of stroke in ELSA-Brasil were probably milder cases with less incapacity than what has been seen in other samples.

Discussion of adherence to treatment is also a complex matter since it is likely that some participants, especially women, had not been prescribed any treatment and thus were not taking any medication. Thus, our results are similar to those of a previous Brazilian study that reported low use of medications for chronic diseases. ${ }^{17}$ Considering that the ELSA-Brasil sample had a higher educational level, higher mean monthly family income and better access to healthcare services, the overall picture for the general population in Brazil is probably worse.

\section{CONCLUSIONS}

In the ELSA-Brasil, the frequency of use of secondary prevention for stroke was low and decreased as the length of time since the stroke increased. Moreover, sex was the variable most associated with use of secondary prevention in this sample. Men reported greater use of medication for secondary prevention of stroke than women, thus suggesting that the rate of prescription of medications for secondary prevention of stroke was low among woman.

\section{REFERENCES}

1. GBD 2015 Mortality and Causes of Death Collaborators. Global, regional, and national life expectancy, all-cause mortality, and cause-specific mortality for 249 causes of death, 1980-2015: a systematic analysis for the Global Burden of Disease Study 2015. Lancet. 2016;388(10053):1459544. PMID: 27733281; doi: 10.1016/S0140-6736(16)31012-1.

2. Feigin VL, Mensah GA, Norrving B, et al. Atlas of the Global Burden of Stroke (1990-2013): The GBD 2013 Study. Neuroepidemiology. 2015;45(3):230-6. PMID: 26505985; doi: 10.1159/000441106

3. Lotufo PA, Goulart AC, Passos VMA, et al. Cerebrovascular disease in Brazil from 1990 to 2015: Global Burden of Disease 2015. Rev Bras Epidemiol. 2017;20Suppl 01(Suppl 01):129-41. PMID: 28658378; doi: 10.1590/1980-5497201700050011.

4. Lotufo PA, Goulart AC, Fernandes TG, Benseñor IM. A reappraisal of stroke mortality trends in Brazil (1979-2009). Int J Stroke. 2013;8(3):15563. PMID: 22297034; doi: 10.1111/j.1747-4949.2011.00757.x.

5. Fernandes TG, Bando DH, Alencar AP, Benseñor IM, Lotufo PA. Income inequalities and stroke mortality trends in Sao Paulo, Brazil, 19962011. São Paulo Med J. 2015;133(6):4579. PMID: 26044779; doi: 10.1111/ijs.12526.

6. Cabral NL, Franco S, Longo A, et al. The Brazilian Family Health Program and secondary stroke and myocardial infarction prevention: a 6-year cohort study. Am J Public Health. 2012;102(12):e90-5. PMID: 23078478; doi: 10.2105/AJPH.2012.301024.

7. Vianna CA, González DA, Matijasevich A. Utilização de ácido acetilsalicílico (AAS) na prevenção de doenças cardiovasculares: um estudo de base populacional [Aspirin use in cardiovascular disease prevention: a population-based study]. Cad Saúde Pública. 2012;28(6):1122-32. PMID: 22666816; doi: 10.1590/S0102-311X2012000600011.

8. Aquino EM, Barreto SM, Benseñor IM, et al. Brazilian Longitudinal Study of Adult Health (ELSA-Brasil): objectives and design. Am J Epidemiol. 2012;175(4):315-24. PMID: 22234482; doi: 10.1093/aje/kwr294.

9. Schmidt MI, Duncan BB, Mill JG, et al. Cohort Profile: Longitudinal Study of Adult Health (ELSA-Brasil). Int J Epidemiol. 2015;44(1):68-75. PMID: 24585730; doi: 10.1093/ije/dyu027.

10. Benseñor IM, Griep RH, Pinto KA, et al. Rotinas de organização de exames e entrevistas no centro de investigação ELSA-Brasil [Routines of organization of clinical tests and interviews in the ELSA-Brasil investigation center]. Rev Saúde Pública. 2013;47 (suppl 2):37-47. PMID: 24346719; doi: 10.1590/S0034-8910.2013047003780. 
11. Mill JG, Pinto K, Griep RH, et al. Aferições e exames clínicos realizados nos participantes do ELSA-Brasil [Medical assessments and measurements in ELSA-Brasil]. Rev Saúde Pública. 2013;47(Suppl 2):54-62. PMID: 24346721; doi: 10.1590/S0034-8910.2013047003851.

12. Santos IS, Bittencourt MS, Oliveira IR, et al. Carotid intima-media thickness value distributions in the Brazilian Longitudinal Study of Adult Health (ELSA-Brasil). Atherosclerosis. 2014;237(1):227-35. PMID: 25244507; doi: 10.1016/j.atherosclerosis.2014.09.004.

14. Stoverinck MJ, Lagro-Janssen AL, Weel CV. Sex differences in health problems, diagnostic testing, and referral in primary care. J Fam Pract. 1996:43(6):567-76. PMID: 8969705.

15. Koutis AD, Isacsson A, Lindholm LH, et al. Use of primary health care in Spili, Crete, and in Dalby, Sweden. Scand J Prim Health Care. 1991;9(4):297-302. PMID: 1792458.

16. Aquino EM, Menezes GM, Amoedo MB. Gênero e saúde no Brasil: considerações a partir da Pesquisa Nacional por Amostra de Domicílios [Gender and health in Brazil: considerations based on the National Household Sampling Survey]. Rev Saúde Pública. 1992;26(3):195-202. PMID: 1342501; doi: 10.1590/S0034-89101992000300011.

17. Bermudez JA, Barros MB. Perfil do acesso e da utilização de medicamentos da população brasileira - contribuições e desafios da PNAUM - Inquérito Domiciliar [Profile of access and use of medicines in the Brazilian population - contributions and challenges of PNAUM Household Survey]. Rev Saúde Pública. 2016;50(suppl 2):2s. PMID: 27982385; doi: 10.1590/s1518-8787.201605000supl2ap.

18. Brasil. Portaria no 3.916. Diário Oficial da União 1998 novembro 10:18 (s. 1, n. 215-E). Available from: http://bvsms.saude.gov.br/bvs/saudelegis/ gm/1998/prt3916_30_10_1998.html. Accessed in 2018 (Jun 11).

19. Brasil. Ministério da Saúde. Secretaria de Ciência, Tecnologia e Insumos Estratégicos. Departamento de Assistência Farmacêutica e Insumos Estratégicos. Relação Nacional de Medicamentos Essenciais: RENAME 2014 / Ministério da Saúde, Secretaria de Ciência, Tecnologia e Insumos Estratégicos, Departamento de Assistência Farmacêutica e Insumos Estratégicos. - 9. ed. rev. e atual. - Brasília: Ministério da Saúde, 2015.

20. Brasil. Ministério da Saúde, Fundação Oswaldo Cruz. Programa Farmácia Popular do Brasil: manual básico/Ministério da Saúde, Fundação Oswaldo Cruz. Brasília: Editora do Ministério da Saúde; 2005. Available from: http://bvsms.saude.gov.br/bvs/publicacoes/ PROGRAMA_FARMACIA_POPULAR.pdf. Accessed in 2018 (Jun 11).

21. Yamauti SM, Barberato-Filho S, Lopes LC. Elenco de medicamentos do Programa Farmácia Popular do Brasil e a Política de Nacional Assistência Farmacêutica [The list of drugs in the Popular Pharmacy Program and the Brazilian National Pharmaceutical Care Policy]. Cad Saúde Pública. 2015;31(8):1648-62. PMID: 26375644; doi: 10.1590/0102-311X00054814.

22. Pinto C du B, Miranda ES, Emmerick IC, Costa N do R, Castro CG. Preços e disponibilidade de medicamentos no Programa Farmácia Popular do Brasil [Medicine prices and availability in the Brazilian Popular Pharmacy Program]. Rev Saúde Pública. 2010;44(4):611-9. PMID: 20585741; doi: 10.1590/S0034-89102010005000021.
23. Guerra AA Jr, Acúrcio F de A, Gomes CA, et al. Disponibilidad de medicamentos esenciales en dos regiones de Minas Gerais, Brasil [Availability of essential drugs in two regions of Minas Gerais, Brazil]. Rev Panam Salud Publica. 2004;15(3):168-75. PMID: 15096289.

24. Dal Pizzol T da S, Trevisol DJ, Heineck I, et al. Adesão a listas de medicamentos essenciais em municípios de três estados brasileiros [Adherence to essential medicines in cities from three Brazilian states]. Cad Saúde Pública. 2010;26(4):827-36. PMID: 20512222; doi: 10.1590/ S0102-311X2010000400024.

25. Gamboa CM, Colantonio LD, Brown TM, Carson AP, Safford MM. RaceSex Differences in Statin Use and Low-Density Lipoprotein Cholesterol Control Among People with Diabetes Mellitus in the Reasons for Geographic and Racial Differences in Stroke Study. J Am Heart Assoc. 2017;6(5). pii: e004264. PMID: 28490523; doi: 10.1161/JAHA.116.004264.

26. Mosca L, Linfante AH, Benjamin EJ, et al. National study of physician awareness and adherence to cardiovascular disease prevention guidelines. Circulation. 2005;111(4):499-510. PMID: 15687140; doi: 10.1161/01.CIR.0000154568.43333.82.

27. Kernan WN, Ovbiagele B, Black HR, et al. Guidelines for the prevention of stroke in patients with stroke and transient ischemic attack: a guideline for healthcare professionals from the American Heart Association/ American Stroke Association. Stroke. 2014;45(7):2160-236. PMID: 24788967; doi: 10.1161/STR.0000000000000024.

28. Chor D, Pinho Ribeiro AL, Sá Carvalho M, et al. Prevalence, Awareness, Treatment and Influence of Socioeconomic Variables on Control of High Blood Pressure: Results of the ELSA-Brasil Study. PLoS One. 2015;10(6):e0127382. PMID: 26102079; doi: 10.1371/journal. pone. 0127382 .

29. Picon RV, Fuchs FD, Moreira LB, Riegel G, Fuchs SC. Trends in prevalence of hypertension in Brazil: a systematic review with meta-analysis. PLOS ONE. 2012;7(10):e48255. PMID: 23118964; doi: 10.1371/journal. pone.0048255.

30. Carrington MJ, Jennings GL, Stewart S. Pressure points in primary care: blood pressure and management of hypertension in 532050 patients from 2005 to 2010. J Hypertens. 2013;31(6):1265-71. PMID: 23552128; doi: 10.1097/HJH.0b013e3283606bc7.

31. Fasce E, Campos I, Ibáñez P, et al. Trends in prevalence, awareness, treatment and control of hypertension in urban communities in Chile. J Hypertens. 2007;25(9):1807-1 1. PMID: 17762644; doi: 10.1097/ HJH.0b013e328244e481.

32. Guo F, He D, Zhang W, Walton RG. Trends in prevalence, awareness, management, and control of hypertension among United States adults, 1999 to 2010. J Am Coll Cardiol. 2012;60(7):599-606. PMID: 22796254; doi: 10.1016/j.jacc.2012.04.026.

33. Lotufo PA, Benseñor IM. Stroke mortality in Brazil: one example of delayed epidemiological cardiovascular transition. Int J Stroke. 2009;4(1):40-1. PMID: 19236497; doi: 10.1111/j.1747-4949.2009.00240.x.

34. Lotufo PA. Stroke is still a neglected disease in Brazil. Sao Paulo Med J. 2015;133(6):457-9.PMID:26760122; doi: 10.1590/1516-3180.2015.13360510. 
35. Kim YY, Park JH, Kang HJ, et al. Level of Agreement and Factors Associated With Discrepancies Between Nationwide Medical History Questionnaires and Hospital Claims Data. J Prev Med Public Health. 2017;50(5):294-302. PMID: 29020761; doi: 10.3961/jpmph.17.024.

Sources of funding: The ELSA-Brasil baseline study was supported by the Brazilian Ministry of Health (Science and Technology Department) and the Brazilian Ministry of Science and Technology and CNPq National Research Council) (grants 01060010.00 RS, 01060212.00 BA, 0106 0300.00 ES, 0106 0278.00 MG, 01060115.00 SP and 01060071.00 RJ).

Marina Gabriela Birck had a fellowship for a Master's degree from CAPES. Dr Paulo Andrade Lotufo and Dr Isabela Martins Benseñor were recipients of fellowship awards from CNPq (productivity bursaries)

\section{Conflict of interest: None}

Date of first submission: March 27, 2018

Last received: June 14, 2018

Accepted: August 6, 2018

\section{Address for correspondence:}

Isabela Martins Benseñor

Centro de Pesquisa Clínica e Epidemiológica, Hospital Universitário,

Universidade de São Paulo

Av. Lineu Prestes, 2.565 - 3o andar

São Paulo (SP) - Brasil

CEP 05508-000

Tel. (+55 11) 3091-9241

E-mail: fgabrielaabreu@gmail.com 